\title{
CHEMICAL CHARACTERISTICS OF WATER-SOLUBLE IONS AND METAL ELEMENTS IN AMBIENT PARTICLES OF SAITAMA, JAPAN DURING THE SPRING ASIAN DUST EVENT, 2017
}

\author{
WEIQIAN WANG \& QINGYUE WANG \\ Graduate School of Science and Engineering, Saitama University, Japan.
}

\begin{abstract}
Metropolitan Tokyo area in Japan suffered from a strong Asian dust event which was lasted for 3 days from May 6 to May 8 in 2017. Asian dust particles are usually originated from the deserts of Mongolia and Kazakhstan and could be absorbed air pollutants contained the metals, water-soluble and organic matters during transport process. In this research, two sampling sites called $10 \mathrm{~F}$ (30 m height above ground level) and roadside in Saitama were selected to collect five different size particles ( $\mathrm{PM}_{1.1}$, $\mathrm{PM}_{1.1-2.0}, \mathrm{PM}_{2.0-3.3}, \mathrm{PM}_{3.3-7.0}$ and the coarse particles $(>7.0 \mu \mathrm{m})$ of three different events: (1) before Asian dust event (B.A.), (2) during Asian dust event (D.A.) and (3) after Asian dust event (A.A.). Eight watersoluble ionic and 23 elemental species in D.A. event were higher than other periods. In D.A. event, the ionic contents in $10 \mathrm{~F}$ were high to $10.3 \mu \mathrm{g} / \mathrm{m}^{3}$ and the elemental contents in roadside were $6.50 \mu \mathrm{g} /$ $\mathrm{m}^{3}$ which were higher than those in roadside. Ionic contents were mainly distributed in $\mathrm{PM}_{1.1}$ with the high contents of secondary particles $\left(\mathrm{NH}_{4}^{+}, \mathrm{NO}_{3}^{-}\right.$and $\left.\mathrm{SO}_{4}{ }^{2-}\right) . \mathrm{Ca}^{2+}, \mathrm{Cl}^{-}$and $\mathrm{Na}^{+}$were more enriched in the coarse particles. Ion balance in D.A. event was more basic in $10 \mathrm{~F}$ and more acidic in roadside. The higher ratios of $\mathrm{NO}_{3}{ }^{-} / \mathrm{SO}_{4}{ }^{2-}$ in $\mathrm{PM}_{1.1}$ were also occurred in D.A. event. Total elements were high $\left(6,050 \mathrm{ng} / \mathrm{m}^{3}\right)$ in $10 \mathrm{~F}$ with the several times increasing in $\mathrm{PM}_{3.3-7.0}$ and the coarse particles, and the great contribution form the crustal elements ( $\mathrm{Al}, \mathrm{Fe}, \mathrm{Na}, \mathrm{Mg}$ and $\mathrm{K}$ ). Enrichment factors (EFs) of trace elements in $\mathrm{PM}_{1.1}$ indicating the anthropogenic sources might be the main sources of those ions. EFs in the coarse particles indicating high concentrations of crustal elements might be affected by the Asian dust event. The analysis of air masses backward trajectories showed that the deserts of Mongolia and Kazakhstan and the northern part of China were the important air pollutant origins in Asian dust events with long-distance transport.
\end{abstract}

Keywords: Asian dust, metal elements, Saitama, water-soluble inorganic ions.

\section{INTRODUCTION}

The metropolitan Tokyo area in Japan suffered from a strong Asian dust event which lasted 3 days from May 6 till May 8 in 2017 [1]. Asian dust, as a meteorological phenomenon, always originates in the deserts of Mongolia and Kazakhstan and affects much of East Asian especially during the spring months every year [2]. The arrival of the Asian dust event in Japan is always marked by the obvious increases of airborne particles, decreases visibility and has an impact on human health [3]. For example, Kanatani detected the impacts of Asian dust particles on allergy symptoms of pregnant women by using lidar observations [4]. Long range transportation of Asian dusts was also found during the pollen scattering seasons in Japan [5]. Watanabe studied Yellow Sand influence on Japanese adult patients with asthma by conducting a telephone survey, finding that about 11-22\% of patients noted worsening lower respiratory symptoms during the strong Asian dust events so-called 'Yellow Sand events' increased when Cryptomeria japonica pollen was present simultaneously in the atmosphere [6]. Dust particles have been suggested that Asian dust particles could be adsorbed anthropogenic atmospheric pollutants during transport process, consisting mostly of metals, watersoluble ions and mineral oxides and organic matters [7]. Many epidemiological studies have provided that the air particles having the linkage to daily particles contents. Tsai reported 
the Asian dust event not only brought a significant amount of $\mathrm{PM}_{2.5}$ but also indicated the sources of sulfur contents which might be affected by the air masses passed the major cities and industrial districts in China mainland [8].

In this article, we focused on the ambient particulates collected from Saitama in Asian dust events of 2017. Specifically, our research purposes are: (1) analyse the 5-stage size distribution and compositions of water-soluble ions and trace elements in ambient particles; (2) analyse the possible sources of water-soluble ions and trace elements in $\mathrm{PM}_{1.1}$; (3) speculate on the source contributions of long-distance transportation of air pollutants with the Asian dust.

\section{MATERIALS AND METHODS}

\subsection{Two sampling sites and the meteorological factors in Saitama}

Two sampling sites (35.87 N and 139.61 E) were in Saitama University, Saitama Prefecture, Japan as shown in Fig 1. One was near to the national route 463 which is one major traffic line in Kanto Region with about 30,000 to 35,000 vehicles per day. The another was in the highest point of the campus about $30 \mathrm{~m}$ in height. The sampling periods were from April 26 to May 17 , and kinds of meteorological factors were collected on Saitama Prefecture air pollution continuous monitoring system [9].

Size-segregated samples of ambient particulates were collected using the quartz fibre filters (Pallflex Product, 2500QATUP) using an Andersen high-volume air sampler (HV-1000R, Shibata Co., Tokyo, Japan) with the flow rate of $0.566 \mathrm{~m}^{3} / \mathrm{min}$. The five stage size-segregated were divided into $\mathrm{PM}_{1.1}, \mathrm{PM}_{1.1-2.0}, \mathrm{PM}_{2.0-3.3}, \mathrm{PM}_{3.3-7.0}$ and the coarse particles $(>7.0 \mu \mathrm{m})$. The sampling periods were divided into three groups: April 26-May 2 (Before Asian dust, B.A.), May 6, May 7 and May 8 (Asian dust, A.D. event) and May 11-17 (after Asian dust event, A.A.).

\subsection{Determination of water-soluble ions and trace elements in Ambient particulates}

Water-soluble ions $\left(\mathrm{SO}_{4}^{2-}, \mathrm{NO}_{3}^{-}, \mathrm{NH}_{4}^{+}, \mathrm{Na}^{+}, \mathrm{Ca}^{2+}, \mathrm{Cl}^{-}, \mathrm{Mg}^{2+}, \mathrm{K}^{+}\right)$in ambient particulates were determined by a liquid chromatograph (IC, Liquid Chromatograph, Shimadzu Co., Tokyo,

(a)

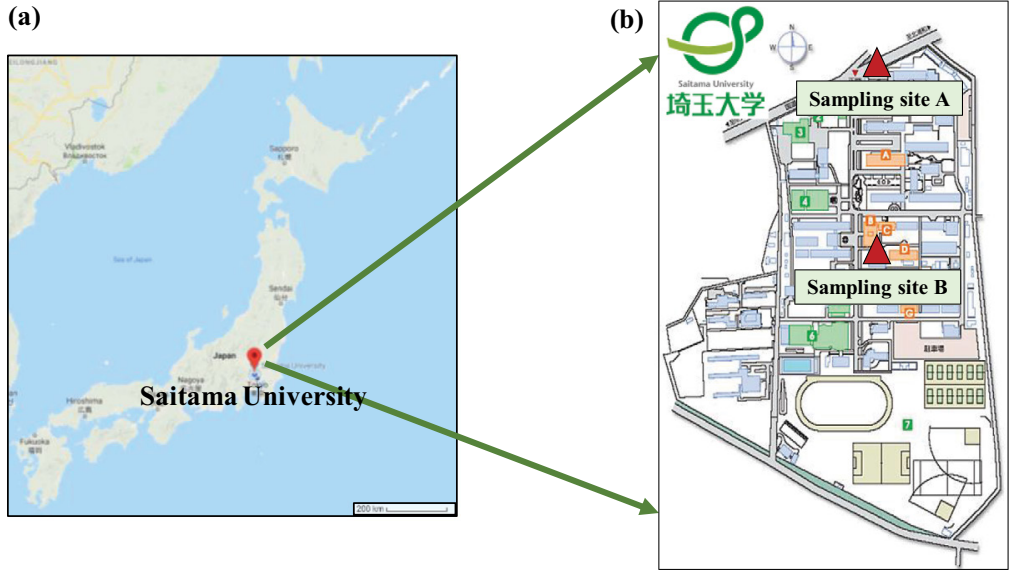

Figure 1: Location of sampling sites: (a) location of Saitama University, Japan; and (b) A and B sampling sites in Saitama University, Japan. 
Japan and Dionex ICS-1600, Thermo Fisher Scientific Co., USA). Ion balance is commonly used to study the acid-base balance of aerosol particles. The ions' mass concentrations into micro-equivalents were calculated to evaluate the cation/anion balance of $\mathrm{PM}_{1.1}$ and the coarse particles [12]. Ion balance was calculated as in follows eqns. (1)-(3):

$$
\begin{gathered}
\text { Cations }=\left(\mathrm{Na}^{+}\right) / 23+\left(\mathrm{NH}_{4}^{+}\right) / 18+\left(\mathrm{K}^{+}\right) / 39+\left(\mathrm{Mg}^{2+}\right) / 24 \times 2+\left(\mathrm{Ca}^{2+}\right) / 40 \times 2 \\
\text { Anions }=\left(\mathrm{SO}_{4}^{2-}\right) / 96 \times 2+\left(\mathrm{NO}_{3}^{-}\right) / 62+\left(\mathrm{Cl}^{-}\right) / 35.5 \\
\text { Ion balance }=\text { Cations/Anions }
\end{gathered}
$$

Trace elemental species in ambient particulate samples were determined with an inductively coupled plasma mass spectrometry (ICP-MS Model Agilent 7700, USA) set in Center for Environmental Science in Saitama (CESS). The analysis method was to refer to these reported in our articles [10].

\subsection{Air masses analysis with the air mass backward trajectories}

HYSPLIT model was selected to acquire a database of air mass backward trajectories by calculating data using the Global Data Assimilation System (GDAS) from the National Oceanic and Atmospheric Administration (NOAA) Air Resources Laboratory's web server. Air mass backward trajectory in each sampling period was calculated at every $24 \mathrm{~h}$ interval, the starting point was made with the altitude of $30 \mathrm{~m}$ which was same as one of the Saitama ambient particulate monitoring station.

\section{RESULTS AND DISCUSSION}

\subsection{SPM, $\mathrm{PM}_{2.5}$ and meteorological factors in Saitama, Japan}

The average values of SPM, $\mathrm{PM}_{2.5}, \mathrm{SO}_{2}, \mathrm{NO}_{2}$, wind speed (WS), temperature (TEP) and humidity (HUM) in Saitama during the different sampling periods of Asian dust events have been shown in Fig 2. In B.A. and A.A. events, $\mathrm{PM}_{2.5}$ and SPM were with the similar contents. SPM and $\mathrm{PM}_{2.5}$ were obviously increased in A.D. event, especially in May 8, the concentrations were high to 33.3 and $18.6 \mu \mathrm{g} / \mathrm{m}^{3}$, was also with the highest $\mathrm{NO}_{2}$ and the $45 \%$ humidity. In $10 \mathrm{~F}$ sampling site, the concentrations of eight species of water-soluble ions in ambient particles were $6.12 \mu \mathrm{g} / \mathrm{m}^{3}$ in B.A. event, $10.3 \mu \mathrm{g} / \mathrm{m}^{3}$ in A.D. event and $6.11 \mu \mathrm{g} / \mathrm{m}^{3}$ in A.A. event and in the roadside sampling side, the ionic contents were $4.74 \mu \mathrm{g} / \mathrm{m}^{3}$ in B.A., $7.75 \mu \mathrm{g} /$ $\mathrm{m}^{3}$ in A.D. and $6.09 \mu \mathrm{g} / \mathrm{m}^{3}$ in A.A. In 10F sampling site, 23 species metal elements in ambient particles were $2.53 \mu \mathrm{g} / \mathrm{m}^{3}$ in B.A., $6.05 \mu \mathrm{g} / \mathrm{m}^{3}$ in A.D. and $1.98 \mu \mathrm{g} / \mathrm{m}^{3}$ in A.A.; and in roadside sampling site, the elements were $2.07 \mu \mathrm{g} / \mathrm{m}^{3}$ in B.A., $5.29 \mu \mathrm{g} / \mathrm{m}^{3}$ in A.D. and $1.67 \mu \mathrm{g} / \mathrm{m}^{3}$ in A.A. It was obvious that the concentration of water-soluble ions and the metal elements in 10F sampling site (about $30 \mathrm{~m}$ height) during the total sampling periods were higher than those in roadside sampling site. Compared with the contents which collected in 2015 [10], the ionic and elemental contents were shown the obvious increase. And, the ions and elements occurred at highest concentrations in A.D. event. 


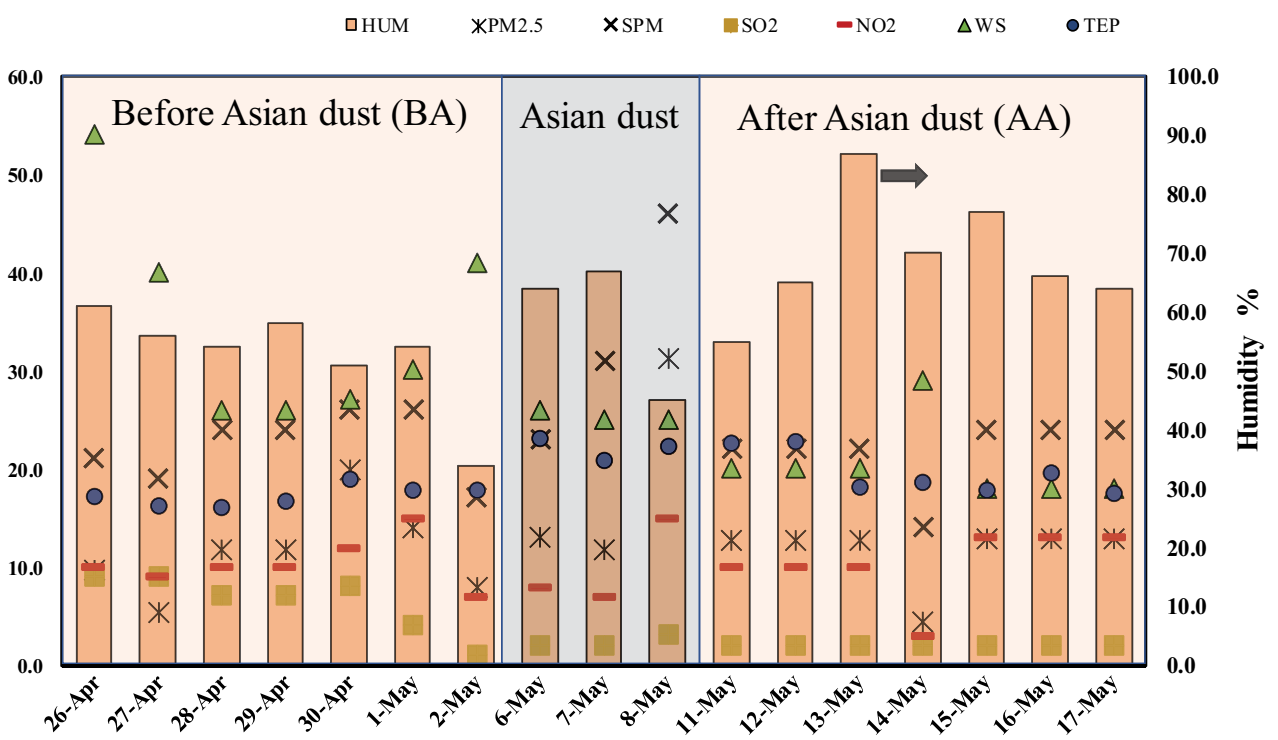

Figure 2: Species and meteorological factors in Saitama, Japan during the different sampling periods.

3.2 Water-soluble ions in $\mathrm{PM}_{1.1}$ and the coarse particles (diameter $>7.0 \mu \mathrm{m}$ )

Water-soluble ions are the important components of ambient particles and play a significant role in ambient air quality and visibility. The ionic contents in ambient particulates have been presented in Fig 3. It was obvious to find that the ions were mainly distributed in $\mathrm{PM}_{1.1}$ of the ambient particles in both $10 \mathrm{~F}$ and roadside sites. Wang also determined the ionic contents that were mainly distributed in $\mathrm{PM}_{1.1}$ of Shanghai, Saitama and Nagasaki in summer of 2015 [10]. Furthermore, $\mathrm{Ca}^{2+}, \mathrm{Cl}^{-}$were mainly located in the coarse particles.

Above $50 \%$ of the total ions in B.A. and A.A. events were distributed in $\mathrm{PM}_{1.1}$ while only about $45 \%$ proportion in Asian dust events with the obvious increasing contents in coarse particles. The highest contents were occurred in A.D. event with the concentrations of $10.3 \mu \mathrm{g} /$ $\mathrm{m}^{3}$ in $10 \mathrm{~F}$ and $7.75 \mu \mathrm{g} / \mathrm{m}^{3}$ in roadside sampling sites. In $\mathrm{PM}_{1.1}$, the secondary particles $\left(\mathrm{NH}_{4}^{+}\right.$,
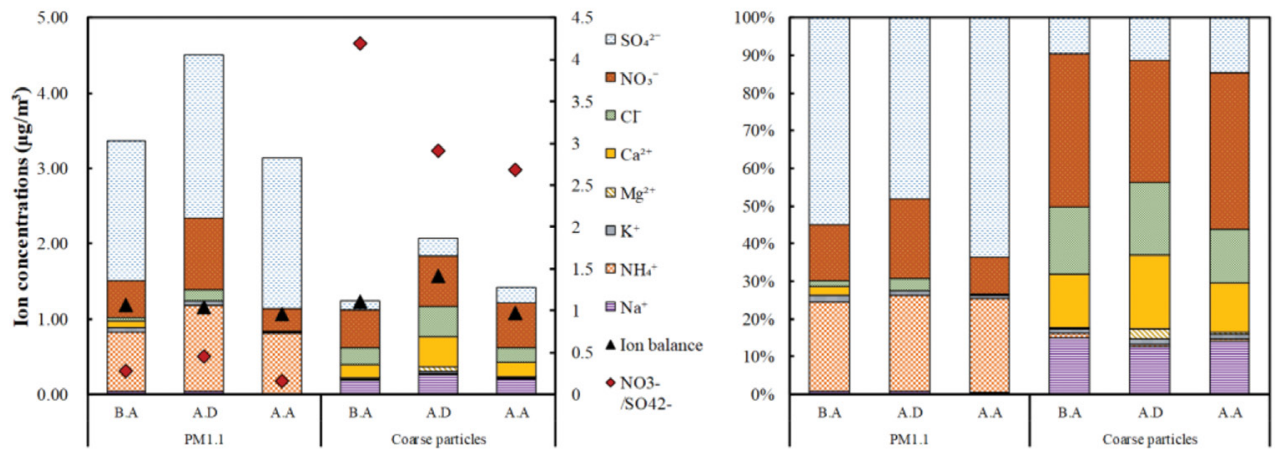

Figure 3: The distribution of ionic species: (a) and the proportion of ionic species and (b) in $\mathrm{PM}_{1.1}$ and the coarse particles collected at $10 \mathrm{~F}$ sampling site. 
$\mathrm{SO}_{4}{ }^{2-}$ and $\mathrm{NO}_{3}^{-}$) as the dominant ions were accounted for $93 \%$ of the total ions among the three sampling periods. Simultaneously, over $80 \% \mathrm{NH}_{4}^{+}$, about $20-30 \% \mathrm{NO}_{3}^{-}$and about $55-82 \% \mathrm{SO}_{4}^{2-}$ were distributed in $\mathrm{PM}_{1.1}$, while $\mathrm{NH}_{4}^{+}, \mathrm{NO}_{3}^{-}$ion in A.D. event were increased about two times. Otherwise, $\mathrm{Cl}^{-}$ion in fine particles which usually caused from coal combustion, were high to $0.146 \mu \mathrm{g} / \mathrm{m}^{3}$ in A.D. event [11]. In coarse particles $(>7.0 \mu \mathrm{m})$, the highest contents were also occurred in A.D. event with the concentrations of $2.07 \mu \mathrm{g} / \mathrm{m}^{3}$ in $10 \mathrm{~F}$ and $1.56 \mu \mathrm{g} / \mathrm{m}^{3}$ in roadside sites. The main ionic contents in coarse particles were $\mathrm{Na}^{+}, \mathrm{Ca}^{2+}$, $\mathrm{Cl}^{-}$and $\mathrm{NO}_{3}^{-}$. Especially, $\mathrm{Ca}^{2+}$, usually originated from crustal particles and construction industry [12], was mainly located in the coarse particles and high to $0.37 \mu \mathrm{g} / \mathrm{m}^{3}$ in roadside and $0.41 \mu \mathrm{g} / \mathrm{m}^{3}$ in $10 \mathrm{~F}$ sampling site resulting about two times higher value than those in other periods. $\mathrm{Na}^{+}$was also mainly enriched in the coarse particles, which was also considered as the main component of sea salt.

In coarse particles, the values of ion balance in $10 \mathrm{~F}$ sampling site, shown in Fig 3, were higher to 1.41 with the great contribution from $\mathrm{Ca}^{2+}, \mathrm{Na}^{+}$and $\mathrm{K}^{+}$ions, which always originated from soils and the value was 1.16 in roadside sampling site in the A.D. period. In general, ionic concentrations in $10 \mathrm{~F}$ were obviously higher than those in roadside sampling site. In $\mathrm{PM}_{1.1}$, the ion balance in $10 \mathrm{~F}$ were in order 1.06 (B.A.) $>1.03$ (A.D.) $>0.96$ (A.A.), the ion balance in roadside were in order 1.19 (A.D.) $>1.05$ (B.A.) $>0.96$ (A.A.). It was indicated that in A.D. event, $\mathrm{PM}_{1.1}$ were more basic in $10 \mathrm{~F}$ and more acidic in roadside. In general, the values of ion balance in coarse particles were higher than those in $\mathrm{PM}_{1.1}$, which could be explained by the abundance of soil particles possibly originated from the dust sources of Asian dust event and could alleviate the acidifying process of the local urban environment. Ion balance in $\mathrm{PM}_{1.1}$ is usually determined by the large proportion of secondary particles $\left(\mathrm{NH}_{4}^{+}, \mathrm{NO}_{3}{ }^{-}\right.$and $\left.\mathrm{SO}_{4}{ }^{2-}\right)$.

$\mathrm{NH}_{4}^{+}$in $\mathrm{PM}_{1.1}$ might be originated from the reaction of $\mathrm{NH}_{3}$ vapour with acidic gases such as $\mathrm{HNO}_{3}, \mathrm{H}_{2} \mathrm{SO}_{4}$ or the reaction of $\mathrm{NH}_{3}$ vapour on the acidic particle surfaces of anthropogenic origin and accumulated in $\mathrm{PM}_{1.1}$. Because ammonium salts could be from the biodegraded processes in the soil, $\mathrm{NH}_{4}^{+}$in coarse particles might be from the wind-generated soil particles. $\mathrm{SO}_{4}{ }^{2-}$ in fine particle could be sourced from homogeneous or heterogeneous chemical transformations of $\mathrm{SO}_{2}$, and in the coarse particles it could be sourced from soil particles. $\mathrm{Al}$ element is a typical crustal component and it has been widely used as a trace for the suspended soil and the long-range transported mineral aerosol. The ratios of $\mathrm{NO}_{3}{ }^{-} / \mathrm{Al}, \mathrm{SO}_{4}{ }^{2-} / \mathrm{Al}$ could be used as an index to show the degree of concentration variations due to the chemical reactions [13]. In $\mathrm{PM}_{1.1}$, the ratios of $\mathrm{NO}_{3}^{-} / \mathrm{Al}, \mathrm{SO}_{4}{ }^{2-} / \mathrm{Al}$ in roadside were higher than those in $10 \mathrm{~F}$. Compared with the B.A. and A.D. periods, the ratios of $\mathrm{NO}_{3}^{-} / \mathrm{Al}, \mathrm{SO}_{4}{ }^{2-} / \mathrm{Al}$ in $\mathrm{PM}_{1.1}$ were higher in A.D. period which indicated that the chemical formation processes were more important in A.D. period. The ratios of $\mathrm{NO}_{3}{ }^{-} / \mathrm{SO}_{4}{ }^{2-}$ usually could be regarded as an indicator of the influence of the mobile and stationary pollution sources and could be dependent on the chemical reactions [13]. In $10 \mathrm{~F}$ sampling site, the ratios of $\mathrm{NO}_{3}{ }^{-} / \mathrm{SO}_{4}{ }^{2}$ in $\mathrm{PM}_{1.1}$ were 0.44 in A.D., 0.27 in B.A. and 0.15 in A.A. events, and roadside sampling sites also showed the same trend. The higher $\mathrm{NO}_{3}{ }^{-} / \mathrm{SO}_{4}^{2}$ also occurred in A.D. events. According to the ion analysis, it was found that ionic contents were more affected by the Asian dust event. Furthermore, size distribution of elemental species in ambient particulates was analysed.

3.3 Metal elemental species in $\mathrm{PM}_{1.1}$ and the coarse particles $(>7.0 \mu \mathrm{m})$ and their possible sources

In this research, 23 elemental species were measured to analyse the size distribution which shown in Fig. 4 and to analyse the main pollutant sources. As with the ionic contents, the 
$10 \mathrm{~F}$

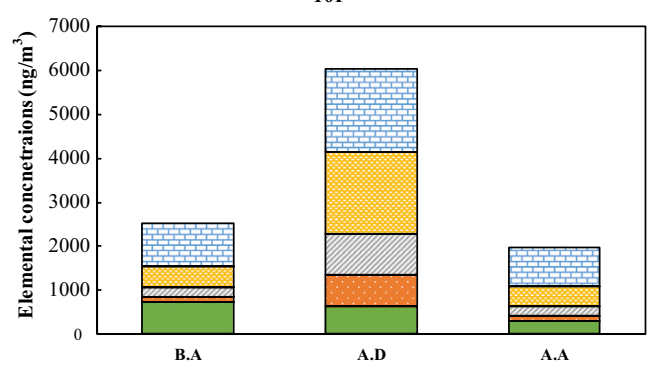

$10 \mathrm{~F}$

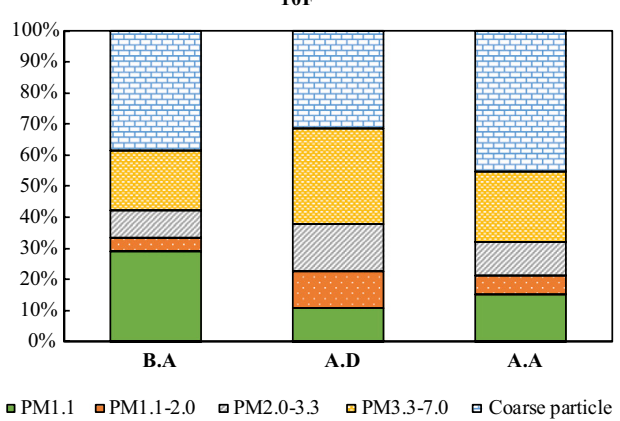

Figure 4: The distribution of elemental species (a) and the proportion of elemental species (b) in ambient particles collected at $10 \mathrm{~F}$ sampling site.

metal elements in $10 \mathrm{~F}$ were also more than those in roadside sampling site during the three sampling periods. In A.D. event, the concentrations of total elements were high to $6,050 \mathrm{ng} /$ $\mathrm{m}^{3}$ in $10 \mathrm{~F}$ and $5,285 \mathrm{ng} / \mathrm{m}^{3}$ in roadside which were over 2.5 times higher than those in other sampling events. Figure 4 showed that in A.D. event, the elemental contents in $\mathrm{PM}_{3.3-7.0}$ were about five times and in coarse particles were about two times than those in other sampling events.

Elemental contents in $\mathrm{PM}_{1.1}$ of A.D. event were nearly similar to those in B.A. events. Na, $\mathrm{Ca}, \mathrm{Mg}, \mathrm{Al}, \mathrm{K}$ and $\mathrm{Fe}$, as the crustal elements which always distributed in the coarse particles [14], were significantly enriched in $\mathrm{PM}_{1.1-2.0}, \mathrm{PM}_{2.0-3.3}, \mathrm{PM}_{3.3-7.0}$ and the coarse particles in A.D. event. The total concentrations of trace elements (V, Cr, Mn, Ni, Cu, As, Cd and Pb) were usually distributed in $\mathrm{PM}_{1.1}$ and also obviously in every stage particle in A.D. event and these trace elements were trend to have negative affect on human health. It was indicated that the crustal elements and the trace elements were affected by the Asian dust event.

Enrichment factors (EFs) method is common to evaluate the strength of the crustal, noncrustal, non-crustal sources. According to method by Lantry and Mackenzie [14], crust sources were primary source of elements when the EFs is $<10$, which means the element is main originated from soil or rock weathering. When the EFs are in the range 10 to $10^{4}$, it means that the element was main originated from the anthropogenic sources.

Following this method, we classified the elements in $\mathrm{PM}_{1.1}$ and coarse particles among these three sampling events in 10F sampling site shown in Fig 5. In $\mathrm{PM}_{1.1}$, EFs of trace elements were in order $\mathrm{Se}>3,000>\mathrm{Sb}>500>\mathrm{Cd}>300>\mathrm{Zn}>\mathrm{Pb}>50>\mathrm{As}>\mathrm{Cu}>10$ in B.A. event; $\mathrm{Se}>4,000>\mathrm{Cd}>\mathrm{Sb}>500 \gg \mathrm{Pb}>\mathrm{Zn}>\mathrm{As}>\mathrm{Ni}>50>\mathrm{Cu}>\mathrm{V}>10$ in A.D. event; $\mathrm{Se}>7,000>\mathrm{Sb}>\mathrm{Cd}>1,000>\mathrm{Pb}>\mathrm{Zn}>100>\mathrm{Cu}>50>\mathrm{V}$ in A.A. event. The results showed that the common anthropogenic pollution elements, such as $\mathrm{As}, \mathrm{Cd}, \mathrm{Cu}, \mathrm{Pb}, \mathrm{Sb}$ and $\mathrm{Zn}$, were mainly affected from the anthropogenic sources (such as, oil and coal combustion, industrial activities and vehicle emissions) among these three events. In coarse particles, EFs of trace elements were in order $\mathrm{Se}>200>\mathrm{Sb}>100>\mathrm{Cd}>\mathrm{Zn}>30 \mathrm{Cu}>10$ in B.A. event; $\mathrm{Se}>\mathrm{Sb}>\mathrm{Zn}>10$ in A.D. event; $\mathrm{Se}>200>\mathrm{Sb}>100>\mathrm{Cd}>\mathrm{Zn}>30 \mathrm{Cu}>10$ in A.A. event. The crustal elements including $\mathrm{Ca}, \mathrm{Al}, \mathrm{Fe}, \mathrm{Na}, \mathrm{Ni}$, Ti and $\mathrm{V}$, which could be mainly affected from the high-intensity of crustal dust. The EFs of $\mathrm{Ca}, \mathrm{Al}, \mathrm{Fe}, \mathrm{Na}, \mathrm{Ti}$ and $\mathrm{V}$ in A.D. event were $<10$ which indicated that these elements were largely originated from natural sources 

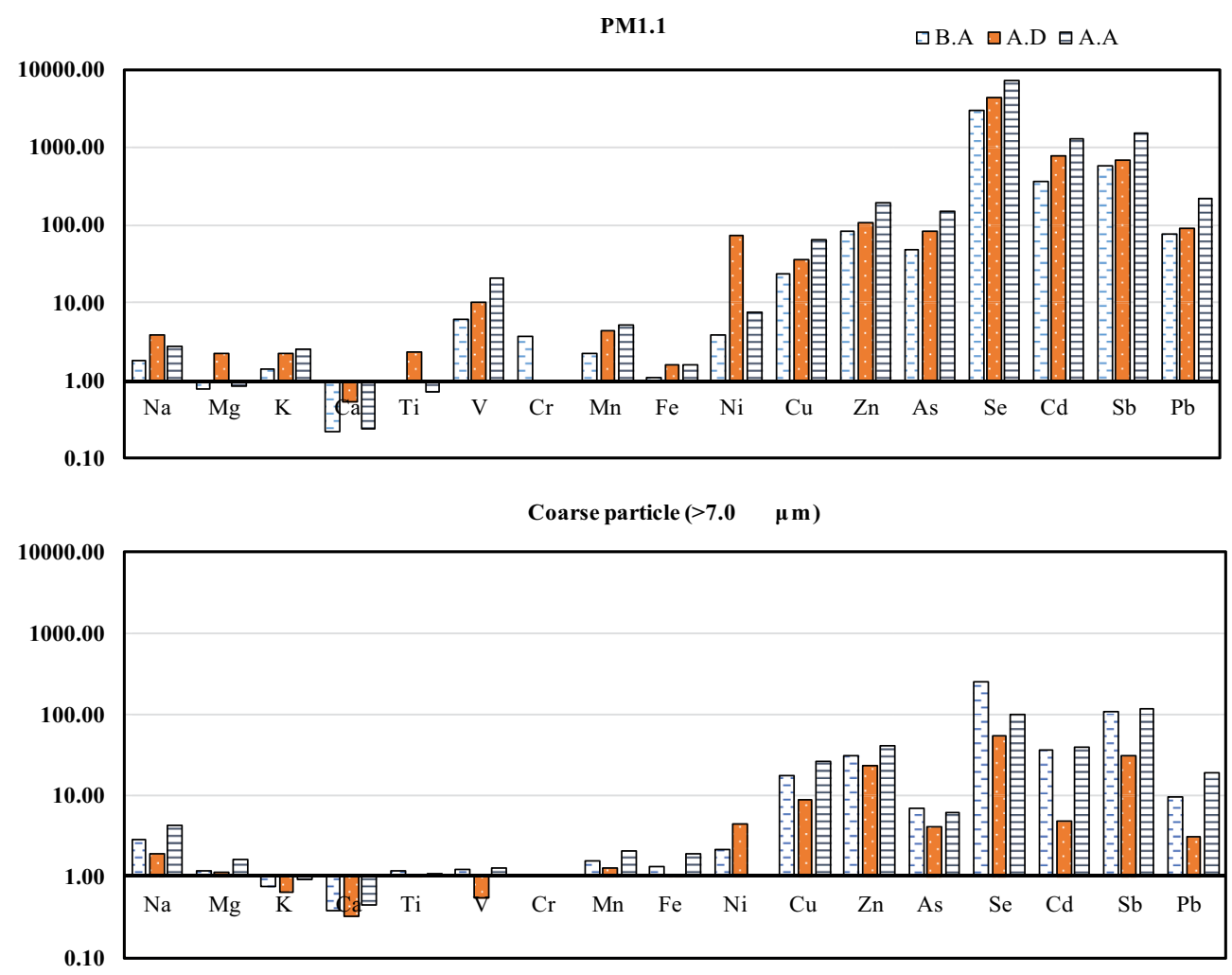

Figure 5: Enrichment factors (EFs) of elemental species in PM1.1 and the coarse particles in $10 \mathrm{~F}$ sampling site.

and rarely transported into the atmosphere. Otherwise, $\mathrm{Pb}, \mathrm{Zn}, \mathrm{Cd}$ and $\mathrm{Cu}$ elements were usually considered relatively volatile metals and they are mainly transported through the atmosphere [15].

Elemental ratios methods are known as the diagnostic tools to estimate the origins of air masses, the local sources and their profiles of possible sources [16]. The values of elemental ratios $(\mathrm{As} / \mathrm{V}, \mathrm{V} / \mathrm{Ni}, \mathrm{Zn} / \mathrm{Pb}$ and $\mathrm{Zn} / \mathrm{Cd})$ in $\mathrm{PM}_{1.1}$ of $10 \mathrm{~F}$ showed the main sources as traffic emissions, gasoline and coal combustion which suggested that the Asian dust event was not lead more affects to the trace elements in $\mathrm{PM}_{1.1}$. With the high concentrations of these crustal element in A.D. event, it was indicated that these elements might be increased with Al elements which affected by Asian dust event. The crustal elements were more affected by the Asian dust event whereas the trace elements in $\mathrm{PM}_{1.1}$ were not showed so obvious change.

\subsection{The polluted air masses caused from long-range transportation}

Among the three sampling periods, water-soluble ions and metal elements in ambient particles were showed the variety of concentrations and distribution characteristics. Ionic and elemental contents were showed the highest concentrations occurred in A.D. event. EFs of element species were represented the anthropogenic sources which were the main sources 

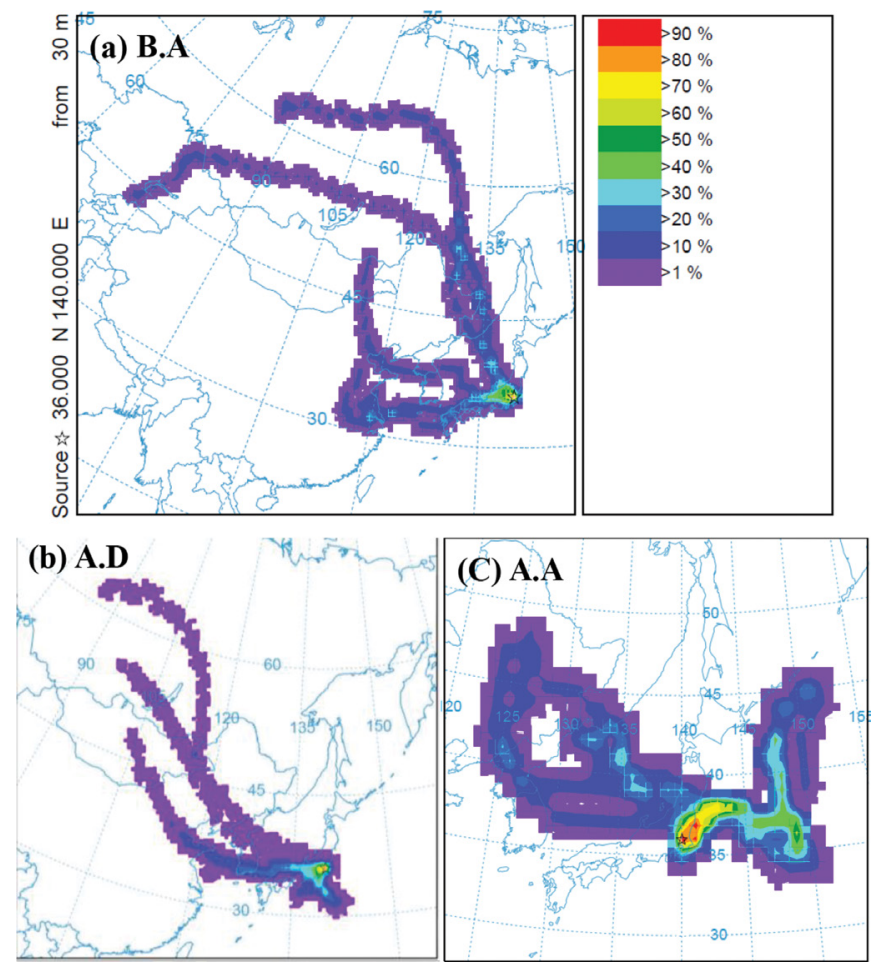

Figure 6: The backward trajectories of air masses during B.A. event (a), A.D. event (b) and A.A. event (c).

including coal and oil combustions, traffic emissions which possibly emitted from local and long-range transport sources. To be better understand, the transport patterns of sampled air masses and the impacts on air quality, backward trajectories of $30 \mathrm{~m}$ above the geographic horizon were calculated and given in Fig 6.

The backward trajectories of air masses in B.A. period were shown in Figure 6(a). Air masses were mainly transported from the Russia and other important way was cross the north and south area of China. Figure 6(b) showed that the air masses were mainly originated from the deserts of Mongolia and Kazakhstan and cross the north area of China. Figure 6(c) showed that the air masses in A.A. event had two main ways. One was from the Pacific Ocean and another from the northeast part of China. In general, according to backward trajectories of air masses, we could indicate that the significant increase in the content of ions and metal elements was affected by the long-range transport sources in the Asian dust period.

\section{CONCLUSION}

In this research, two ambient particles sampling sites with different height in Saitama were chosen to analyse the effects by this Asian dust event. The ambient particles were divided into five stages shown as $\mathrm{PM}_{1.1}, \mathrm{PM}_{1.1-2.0}, \mathrm{PM}_{2.0-3.3}, \mathrm{PM}_{3.3-7.0}$ and the coarse particles $(>7.0 \mu \mathrm{m})$ in three sampling periods (1) before Asian dust event (B.A.), (2) Asian Dust event (A.D.) and (3) after Asian dust event (A.A.). Saitama Prefecture air pollution continuous monitoring system showed that SPM and $\mathrm{PM}_{2.5}$ values were obvious increased in A.D. event. Eight 
water-soluble ionic species and 23 elemental species occurred in the highest values in A.D. event. The contents in $10 \mathrm{~F}$ (with about $30 \mathrm{~m}$ height) were obviously higher than those in another site. The ionic contents in $10 \mathrm{~F}$ were high to $10.3 \mu \mathrm{g} / \mathrm{m}^{3}$ and were mainly distributed in $\mathrm{PM}_{1.1}$ with the high contents of secondary particles $\left(\mathrm{NH}_{4}^{+}, \mathrm{NO}_{3}^{-}\right.$and $\left.\mathrm{SO}_{4}^{2-}\right)$ which accounted for $93 \%$ of the total ions in $\mathrm{PM}_{1.1}$. The main ionic contents in coarse particles were $\mathrm{Na}^{+}, \mathrm{Ca}^{2+}, \mathrm{Cl}^{-}$and $\mathrm{NO}_{3}^{-} . \mathrm{Ca}^{2+}$ which usually originated from the crust particles were mainly located in the coarse particles and high to $0.37 \mu \mathrm{g} / \mathrm{m}^{3}$ in roadside and $0.41 \mu \mathrm{g} / \mathrm{m}^{3}$ in $10 \mathrm{~F}$ with about two times higher than other events. $\mathrm{Na}^{+}$, originated from sea salt, was also enriched in the coarse particles. In coarse particles, the values of ion balance in $10 \mathrm{~F}$ sampling site were high to 1.41 with the great contribution of $\mathrm{Ca}^{2+}, \mathrm{Na}^{+}$and $\mathrm{K}^{+}$while the values in $\mathrm{PM}_{1.1}$ were unity to 1 at three sampling events. The higher ratios of $\mathrm{NO}_{3}{ }^{-} / \mathrm{SO}_{4}{ }^{2-}$ in $\mathrm{PM}_{1.1}$ were also found in A.D. event which indicated that the traffic emission was an important source at this special period. Total elements were high to $6,050 \mathrm{ng} / \mathrm{m}^{3}$ in $10 \mathrm{~F}$ with the high contents in $\mathrm{PM}_{3.3-7.0}$ and in the coarse particles. EFs of elemental species in PM $_{1.1}$ were very high but very close at three sampling periods which indicated the responsibility of anthropogenic sources. With the high concentrations of the crustal element in A.D. event, it was indicated that the elements might be increased with $\mathrm{Al}$ elements which was affected by Asian dust event. EFs in the coarse particles indicated that the high concentrations of crustal elements also might be affected by the Asian dust event. According to the backward trajectories of air masses, it can be concluded that the significant increase in the content of ions and metal elements in the Asian dust period was affected by the long-range transport sources.

\section{ACKNOWLEDGEMENT}

Some works of this study were supported by the Special Funds for Innovative Area Research (No. 20120015, FY2008-FY2012), Grant-in-Aid for Scientific Research (B) (No. 24310005, FY2012-FY2014; No. 15H05119, FY2015-FY2017, No. 18H03384, FY 2018 FY2020) of the Japan Society for the Promotion of Science (JSPS) and Japanese Ministry of Education, Culture, Sports, Science and Technology (MEXT), Japan.

\section{REFERENCES}

[1] Japan Meteorological Agency, https://www.jma.go.jp/jma/menu/menureport.html

[2] Otani, Shinji, et al., Dust storms from degraded drylands of Asia: dynamics and health impacts. Land, 6(4), p. 83, 2017.

[3] Shimizu, Atsushi, et al., Variations of Dust Extinction Coefficient Estimated by Lidar Observations over Japan, 2007-2016. SOLA, 13, pp. 205-208, 2017.

[4] Kanatani, Kumiko T., et al., Effect of desert dust exposure on allergic symptoms: a natural experiment in Japan. Annals of Allergy, Asthma \& Immunology, 116(5), pp. 425430, 2016.

[5] A, Wang, Qingyue, et al. Size-segregated Allergenic Particles Released from Airborne Cryptomeria japonica Pollen Grains during the Yellow Sand Events within the Pollen Scattering Seasons. Asian Journal of Atmospheric Environment (AJAE), 7(4), pp.191198, 2013.

[6] Watanabe, Masanari, et al., Correlation between Asian dust storms and worsening asthma in Western Japan. Allergology International, 60(3), pp. 267-275, 2011.

[7] Dias, G.M., Differentiating natural and anthropogenic sources of metals to the environment. Human and Ecological Risk Assessment, 9(4), pp. 699-721, 2003. 
[8] Tsai, Y.I., Characterization of Asian dust storm and non-Asian dust storm PM2.5 aerosol in southern Taiwan. Atmospheric Environment, 40(25), pp. 4734-4750, 2006.

[9] Saitama Prefecture air pollution continuous monitoring system, http://www.taiki-kansi. pref.saitama.lg.jp/

[10] Wang, qingyue \& Weiqian, Wang, Survey of inorganic components in atmospheric particles of three urban areas caused by winter energy consumption in China and Japan. WIT Transactions on Ecology and the Environment, 217, pp. 469-479, 2018.

[11] Squizzato, S., et al., Factors determining the formation of secondary inorganic aerosol: a case study in the Po Valley (Italy). Atmospheric chemistry and physics, 13(4), pp. 1927-1939, 2013.

[12] Zhang, Yy., Chemical characteristics of PM2.5 during 2015 spring festival in Beijing, China. Aerosol and Air Quality Research, 17(5), pp. 1169-1180, 2017.

[13] Wang, Y., The variation of characteristics and formation mechanisms of aerosols in dust, haze, and clear days in Beijing. Atmospheric Environment, 40(34), pp. 65796591, 2006.

[14] Tan, J-H., Source of atmospheric heavy metals in winter in Foshan, China. Science of the Total Environment, 493, pp. 262-270, 2014.

[15] Bilos, C., Sources, distribution and variability of airborne trace metals in La Plata City area, Argentina. Environmental pollution, 111(1), p. 1, 2001.

[16] Arditsoglou, A., Levels of total suspended particulate matter and major trace elements in Kosovo: a source identification and apportionment study. Chemosphere, 59(5), pp. 669-678, 2005. 